\title{
COMPARISON OF WATER AND OIL HYDRAULIC POSITION SERVOS
}

\author{
Esa Mäkinen, Tapio Virvalo, Matti Vilenius \\ IHA, Tampere University of Technology \\ P.O.Box 589, 33101 Tampere, Finland \\ Fax int-358-3-365240, e-mail makinen@cc.tut.fi, virvalo@cc.tut.fi
}

\begin{abstract}
So far not very much research has been done and not many experimental results are available on water hydraulic position servos. In this paper the feasibility of a design method similar to that used in oil hydraulic position servos is studied in water hydraulics. The P-controller water hydraulic position servo cylinder is designed in the way well known from oil hydraulics. The P-controller is used because it is simple, widely in use and good for comparison.

The design process, theoretical equations and experimental results are presented. The variation rate in the position accuracy, settling time and dynamic behavior with different steps is shown. The specifications arrived at position accuracy, settling time and dynamics for the water hydraulic position servo system are compared with the oil hydraulic specifications. The applicability of the design method and the parameter approximations used in the P-controlled water hydraulic position servos is discussed.
\end{abstract}

\section{KEYWORDS}

Water hydraulic cylinder, water hydraulic position servo

\section{NOMENCLATURE}

$\begin{array}{ll} \pm 3 \sigma & \text { Three-time standard deviation range } \\ \omega_{\mathrm{d}} & \text { Non damped natural frequency }[\mathrm{rad} / \mathrm{s}] \\ \omega_{\mathrm{n}} & \text { Natural frequency }[\mathrm{rad} / \mathrm{s}] \\ \delta_{\mathrm{n}} & \text { Natural damping } \\ \Delta \mathrm{p}_{1} & \text { Pressure drop on piston side }[\mathrm{Pa}] \\ \Delta \mathrm{p}_{2} & \text { Pressure drop on rod side }[\mathrm{Pa}]\end{array}$

$\begin{array}{ll}\Delta \mathrm{p}_{\mathrm{n}} & \text { Nominal pressure drop }[\mathrm{Pa}] \\ \mathrm{A} & \text { Average area of piston }\left[\mathrm{m}^{2}\right] \\ \mathrm{A}_{1} & \text { Area on piston side }\left[\mathrm{m}^{2}\right] \\ \mathrm{A}_{2} & \text { Area on rod side }\left[\mathrm{m}^{2}\right] \\ \mathrm{b} & \text { Coefficient of viscose friction }[\mathrm{Ns} / \mathrm{m}] \\ \mathrm{B}_{\mathrm{eff}} & \text { Effective and bulk modulus }[\mathrm{Pa}] \\ \mathrm{B}_{\mathrm{w}} & \text { Bulk modulus of water }[\mathrm{Pa}] \\ \mathrm{C}(\mathrm{s}) & \text { Transfer function of controller } \\ \mathrm{er}_{\mathrm{L}} & \text { Error due load force } \\ \mathrm{er}_{\mathrm{v}} & \text { Error due hysteresis of servo valve }\end{array}$




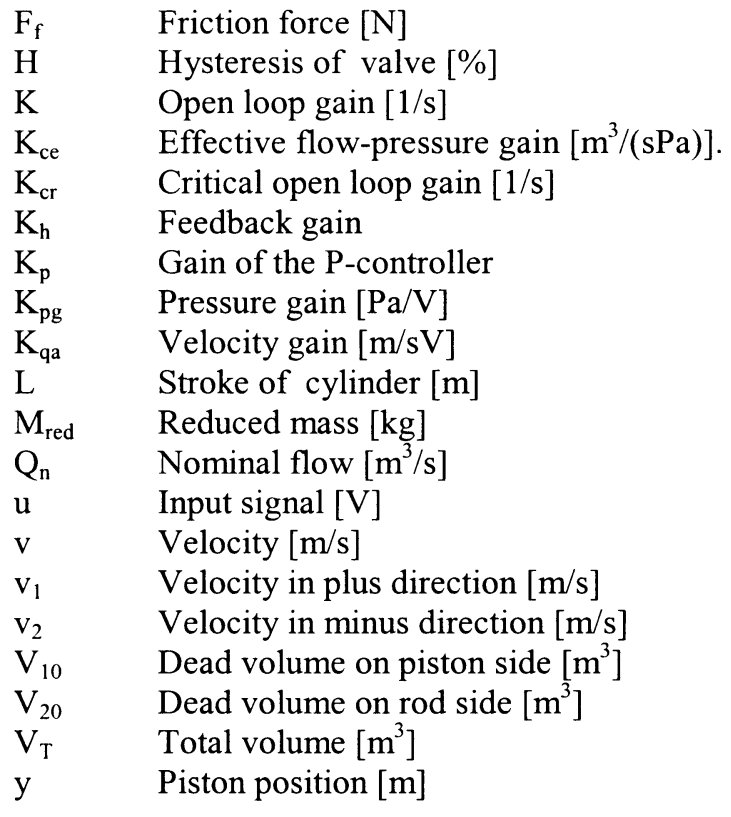

\section{INTRODUCTION}

The design of oil hydraulic position servos is a wellknown process. A useful design method in practical applications, implemented with commercially available components, is based on the linear model of the actuator, general linear control theory and the specifications of the servo valve given by the manufacturer. Linear $2^{\text {nd }}$ - and $3^{\text {rd }}$-order models are used to describe the behavior of the velocity and position of the piston.

The main characteristics used to describe the quality of the position control system are position accuracy, settling time and dynamic behavior. In the comparison of different position control systems the accuracy in relation to maximum velocity and the settling time in relation to natural frequency and damping must be considered.

The parameters of the linear models are natural frequency, damping and velocity gain $\mathrm{K}_{\mathrm{qa}}$, Figure 1 .

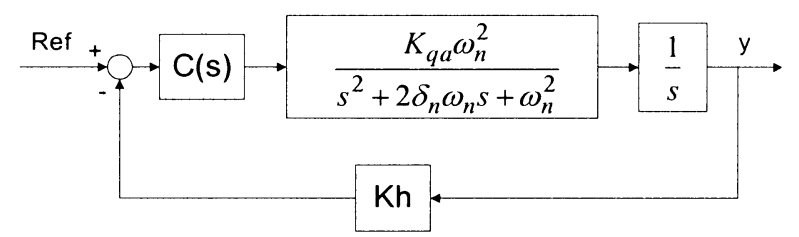

Figure 1 Linear model of the position servo

The model is based on the assumption that the dynamics of the control valve is clearly higher ( $3 \ldots 5$ times) than the dynamics of the cylinder drive.

In oil hydraulics reasonably good approximations can be found for the parameters of the linear model in spite of many non-linearities, but in water hydraulics there is not very much research available on these parameters, at least for the designer of practical applications.

These parameters can be evaluated based on the information available on the control valve and system dimensioning, Figure 2.

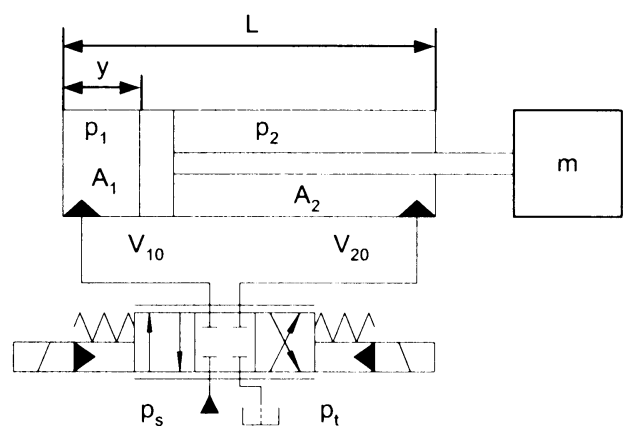

Figure 2 Valve-controlled cylinder

The specifications of the system studied are:

- Cylinder 63/36-500 mm

- Pipes between the valve and cylinder, length $=0.7 \mathrm{~m}$ and $\mathrm{d}_{\text {in }}=12 \mathrm{~mm}$ (same on both sides)

- $\mathrm{V}_{10}=7.529 \mathrm{e}-5 \mathrm{~m}^{3}$ (including pipes)

- $\mathrm{V}_{20}=1.1206 \mathrm{e}-4 \mathrm{~m}^{3}$ (including pipes)

- Supply pressure $\mathrm{p}_{\mathrm{s}}=8 \mathrm{MPa}$

- Tank pressure $\mathrm{p}_{\mathrm{t}}<0.15 \mathrm{MPa}$

- Nominal inertia load $\mathrm{m}=850 \mathrm{~kg}$

- Servo valve

- $\mathrm{Q}_{\mathrm{n}}=19 \mathrm{l} / \mathrm{min}\left(\Delta \mathrm{p}_{\mathrm{n}}=35 \mathrm{bar} / \mathrm{control}\right.$ notch $)$

- $\quad \mathrm{H}=3 \%$

- Bulk modulus of water $\mathrm{B}_{\mathrm{w}}=2.1 * 10^{9} \mathrm{~Pa}$

Using the basic theory, rather unambiguous equations can be derived for the natural frequency and damping.

Natural frequency is

$$
\omega_{n}=\sqrt{\frac{A_{1}^{2} B_{c f f}}{M_{r e d}\left(y A_{1}+V_{10}\right)}+\frac{A_{2}^{2} B_{c f f}}{M_{r e d}\left((L-y) A_{2}+V_{20}\right)}}
$$

However, some parameters of these equations are not necessarily so unambiguous. In oil hydraulics, for example, the effective bulk modulus is hard to obtain. The bulk modulus of oil is $1.5 \mathrm{e} 9 \mathrm{~Pa}$, but typically used effective values are only $1-1.2 \mathrm{e} 9 \mathrm{~Pa}$. In order to get good correspondence between measured and calculated results, additional dead volumes (not exactly representing the real physical ones) must be used. The natural frequency of the system studied is shown in Figure 3. This diagram is based on Equation 1. The effective bulk modulus is approximated to be $80 \%$ of the bulk modulus of the water. 


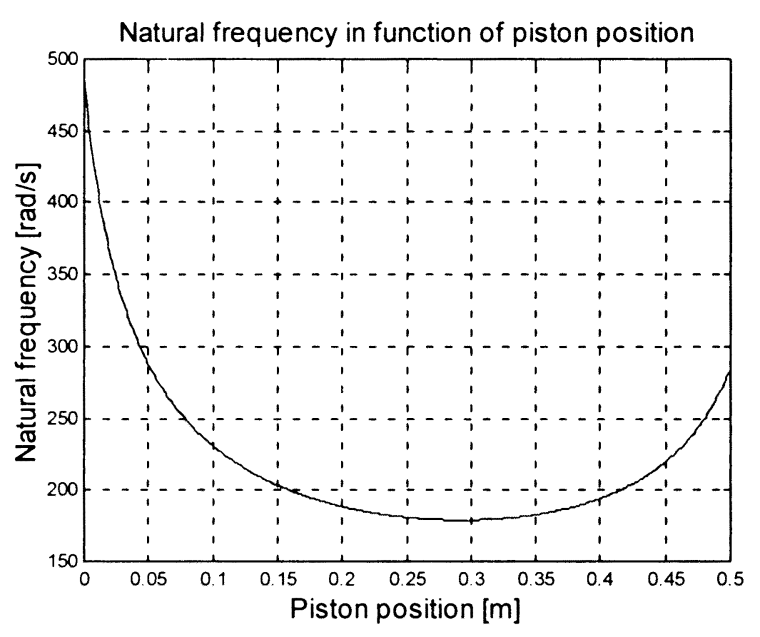

Figure 3 Natural frequency of drive studied

The minimum value of the natural frequency is $180 \mathrm{rad} / \mathrm{s}$.

The natural damping is:

$$
\delta_{n}=\frac{K_{c e}}{A} \sqrt{\frac{B_{e f f} M_{r e d}}{V_{T}}}+\frac{b}{4 A} \sqrt{\frac{V_{T}}{B_{e f f} M_{r e d}}}
$$

The equation of the damping is difficult to use in practice because it is not easy to obtain values for the parameters of the equation. Very often the relative damping is merely estimated based on experience. The typical values of the damping in oil hydraulic cylinder drives are 0.1-0.2. In water hydraulics these values can be expected to be even somewhat lower. In this study the value $\delta_{n}=0.1$ is used.

The minus-movement is slower in proportion to the square of the cylinder areas. Usually the same velocity in both directions is desired, which can be achieved by taking into consideration Equation 3.

$$
v=v_{2}=v_{1} \sqrt{\frac{A_{2}}{A_{1}}}
$$

The velocity gain $\mathrm{K}_{\mathrm{qa}}$ is the ratio of maximum velocity to the maximum control signal. It depends on the size of the cylinder and valve $\left(\mathrm{Q}_{\mathrm{n}}\right)$ and the nominal and actual pressure drops of the valve. In the plus-movement when the velocity difference is compensated the velocity gain can be calculated as follows

$$
K_{q a}=\frac{v_{\max }}{u_{\max }}=\frac{Q_{n} \sqrt{\frac{\Delta p_{2}}{\Delta p_{n}}}}{A_{2} u_{\max }} \sqrt{\frac{A_{2}}{A_{1}}}
$$

In this case, when all the components have already been chosen and the loading condition is known, the actual pressure drop can be calculated in the following way.
When a symmetric 4-way valve controls a normal one-rod cylinder, the pressure in both chambers of the cylinder reaches a certain steady state value $/ 2 \%$. If there is no external force, these pressures depend only on the supply pressure and the ratio of the cylinder chamber areas. In a constant supply pressure system, pressures are set so that the maximum velocity is at the plus-movement (stroke outwards). The velocity of the plus-movement is calculated as follows

$$
v_{1}=\frac{Q_{2}}{A_{2}}=\frac{Q_{n} \sqrt{\frac{\Delta p_{2}}{\Delta p_{n}}}}{A_{2}}
$$

Where

$$
\Delta p_{2}=\frac{\frac{A_{1}}{A_{2}}}{1+\left(\frac{A_{1}}{A_{2}}\right)^{3}} p_{s}
$$

The velocity gain of the system is $K_{q a}=0.01 \mathrm{~m} / \mathrm{sV}$ when the maximum control signal is $10 \mathrm{~V}$.

\section{DESIGN OF THE P-CONTROLLER}

Typical of hydraulic cylinder drives is fairly high natural frequency and low damping. The main effort in designing a controller for a demanding servo application goes into finding a good and practical method for increasing system damping.

Stability and dynamic behavior depends on the natural frequency and damping. These parameters provide the basis also for the design of more sophisticated controllers.

In the case of the P-controller, the dynamics of the system can easily be designed using the well-known RouthHurwiz criterion for critical open loop gain.

$$
K_{c r}=2 \delta_{n} \omega_{n}=2 \cdot 0.1 \cdot 180=36 \mathrm{rad} / \mathrm{s}
$$

The allowed open loop gain is

$$
K \prec \frac{1}{3} K_{c r}=121 / s
$$

When the open loop gain has been chosen, the desired accuracy can be considered.

The open loop gain is defined as follows

$$
K=K_{p} K_{h} K_{q a}
$$

The type number of the position servo is one, which means that theoretically the error is zero. In practice there is error $\mathrm{er}_{v}$ due to nonlinearities of the control valve and error $\mathrm{er}_{\mathrm{L}}$ due to load changes. 
The hysteresis and nonlinearities of the servo valve typically cause the most significant error, $\mathrm{er}_{\mathrm{v}}$. This error depends on the product of gains $\mathrm{K}_{\mathrm{p}} \mathrm{K}_{\mathrm{h}}$ and the hysteresis $\mathrm{H}$ of the servo valve. From Equation 9 we get

$$
K_{p} K_{h}=\frac{K}{K_{q a}}=\frac{12}{0.01}=1200 \frac{\mathrm{V}}{\mathrm{m}}
$$

The error $\mathrm{er}_{\mathrm{v}}$ is

$$
e r_{v}=\frac{H u_{\max }}{K_{P} K_{h}}=\frac{0.3}{1200} \mathrm{~mm}=0.25 \mathrm{~mm}
$$

The error $\mathrm{er}_{\mathrm{L}}$ due to friction forces only is

$$
e r_{L}=\frac{F_{f}}{K_{P} K_{h} K_{p g} A}=\frac{1000}{1200 \cdot 32 \cdot 10^{6} \cdot 0.0026}=0.01 \mathrm{~mm}
$$

where $\mathrm{K}_{\mathrm{pg}}$ is the pressure gain. Its value can be obtained from the specifications of the servo valve, but a good approximation in oil hydraulics is the following

$$
K_{p g}=\frac{0.8 p_{s}}{0.02 u_{\max }}=\frac{0.8 \cdot 8 \cdot 10^{6}}{0.02 \cdot 10} \frac{P a}{V}=32 \frac{M P a}{V}
$$

It is necessary to consider also the speed of the system. The peak time describes the maximum ability of the system to respond to the stepwise inputs

$$
T_{P}=\frac{\pi}{\omega_{d}}=\frac{\pi}{\omega_{n} \sqrt{1-\delta_{n}^{2}}}=\frac{\pi}{180 \sqrt{1-0.1^{2}}}=18 \mathrm{~ms}
$$

In practical position servo applications, often no overshoot is wanted. In demanding applications, if there is no overshoot, settling times are 3 to 6 times the peak time.

\section{EXPERIMENTAL RESULTS}

The P-controlled water hydraulic position servo was designed using $850 \mathrm{~kg}$ and $2850 \mathrm{~kg}$ masses. Table 1 gives the desired or expected specifications calculated in the way presented above.

Table 1 Specifications calculated

\begin{tabular}{lll}
\hline & $\mathrm{m}=850 \mathrm{~kg}$ & $\mathrm{~m}=2850 \mathrm{~kg}$ \\
\hline $\mathrm{K}[1 / \mathrm{s}]$ & 12 & 6.5 \\
$\mathrm{er}_{\mathrm{v}}[\mathrm{mm}]$ & 0.25 & 0.46 \\
$\mathrm{~T}_{\mathrm{p}}[\mathrm{ms}]$ & 18 & 32 \\
$\mathrm{v}_{\max }[\mathrm{m} / \mathrm{s}]$ & 0.1 & 0.1 \\
\hline
\end{tabular}

Both saturated and non-saturated movements (short and long strokes) in both directions near the middle of the cylinder stroke were studied. Before the tests, the system was de-aired carefully.

In the following, typical responses with $m=850 \mathrm{~kg}$ are shown for short and long strokes. The repeatability of the position error and the settling time were measured with two masses: $\mathrm{m}=850 \mathrm{~kg}$ and $2850 \mathrm{~kg}$.

The position, error and velocity responses in both directions with a short stroke are shown in Figures 4-6 and with a longer stroke in Figures 7-9.

In both cases there is no overshoot, so the basic dynamic requirement is fulfilled. In short movements there are more oscillations. The damping is greater in the minusmovement, which can be seen from the zoomed error curves and from the velocity curves.

With short steps, even the direction of the velocity changes during the oscillations when the position is near the desired value. In practice this causes more variation in the settling time.

The zoomed error curve is presented in Figure 5. The desired error range is marked with dash-dotted lines. In the plus-movement (upper curve), the oscillation that occurs just before the desired error range is reached is shown. Depending on the timing of this oscillation, the settling time is shorter or longer.

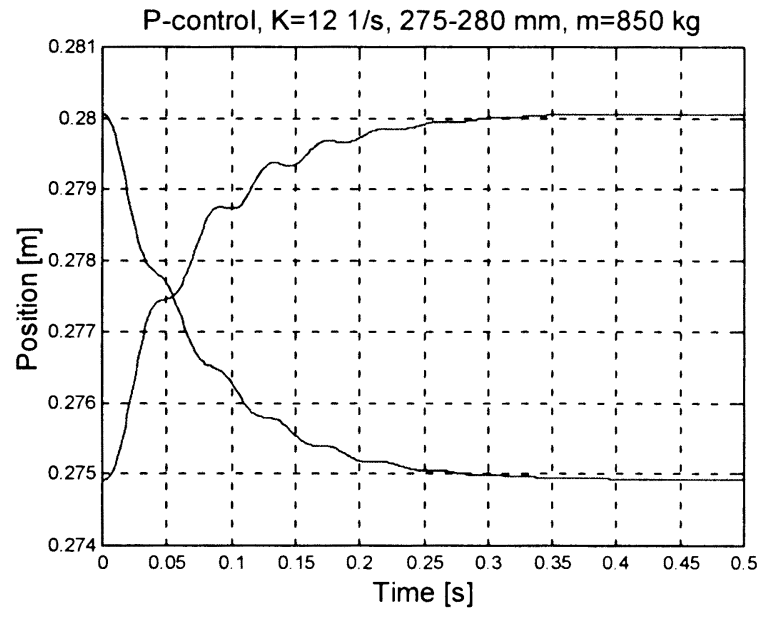

Figure 4 Position in short non-saturated responses

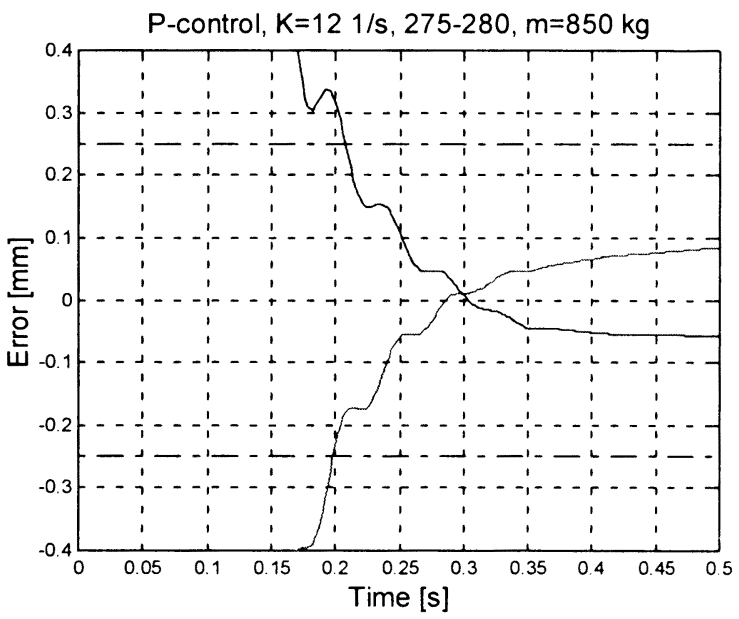

Figure 5 Error in non-saturated in- and outward responses 


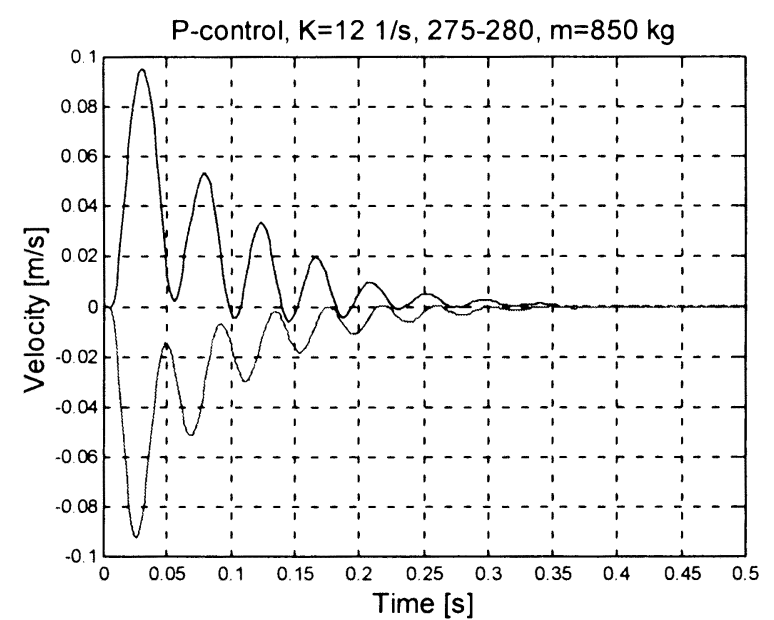

Figure 6 Velocity in short non-saturated responses

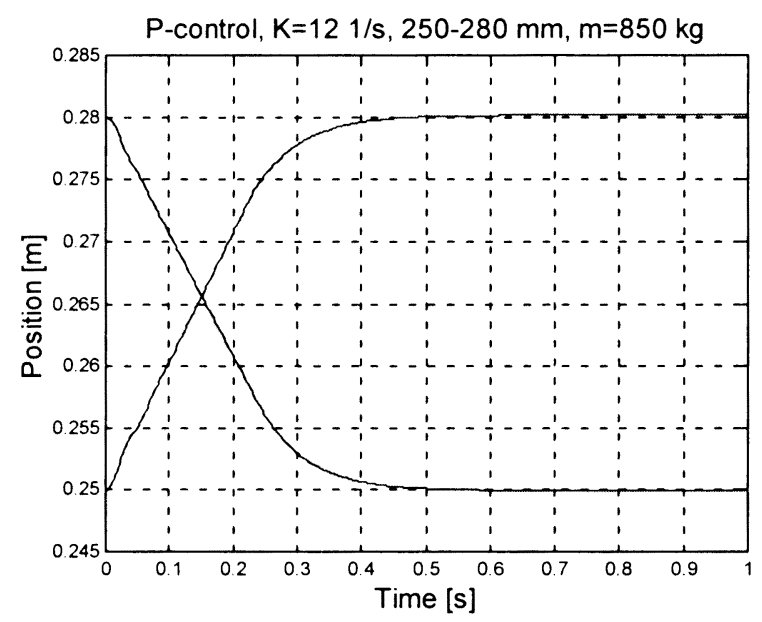

Figure 7 Position responses in saturated movements

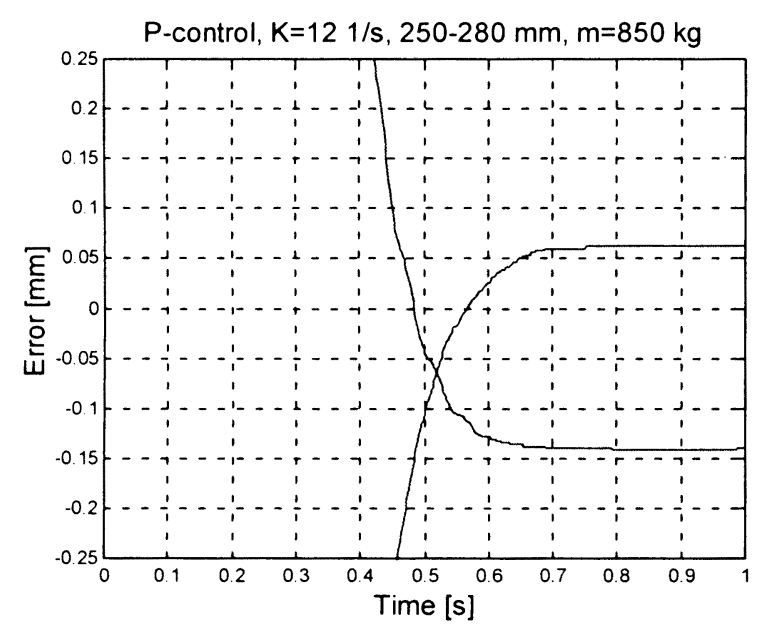

Figure 8 Error in saturated movements

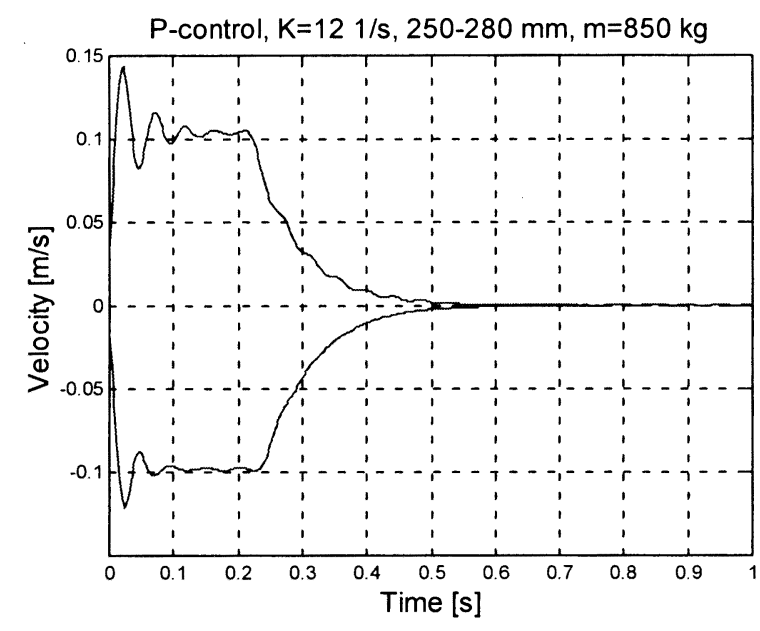

Figure 9 Velocity responses in saturated movements

With longer strokes the valve saturates and the cylinder reaches its maximum value. The calculated maximum velocity and the velocity $( \pm 0.1 \mathrm{~m} / \mathrm{s})$ derived from the measured curve (Figure 9) are very close to each other.

The repeatability of the position error with the $850 \mathrm{~kg}$ mass is shown in Figure 10 and that with the $2850 \mathrm{~kg}$ in Figure 11. The error is determined at the moment that is $0.6 \mathrm{~s}$ after the settling time has been reached. The time delay was chosen to be as short as possible but long enough so that all oscillations are damped.

In the position error analysis 20 movements (consisting of short and long movements) in both directions are used. The plus-movement is the lower (triangle-marked) curve and the minus-movement is the upper (rectangle-marked) curve. The three-time standard deviation range $\pm 3 \sigma$ was determined separately for both directions. The $\pm 3 \sigma$ error range is $(-0.23 \mathrm{~mm}, 0.25 \mathrm{~mm})$ with the $850 \mathrm{~kg}$ mass and with the $2850 \mathrm{~kg}$ mass it is ( $-0.35 \mathrm{~mm}$ to $0.26 \mathrm{~mm})$. With the smaller mass the measured error range corresponds to the desired value and with the bigger mass the measured error range is clearly smaller than the desired value.

Variation of the settling time is shown in Figures 12 and 13. The settling time is the time after which the position error is permanently within the desired limits. Settling times were determined only for the short non-saturated responses. In these figures plus-movements are on the left and minus-movements on the right side of the Figures. In plus-movements the deviation (three-time standard deviation range $\pm 3 \sigma$ ) is clearly greater than in minusmovements. The mean value of the settling time in the plus-movement is shorter with smaller mass, but with greater mass the situation is the opposite. In all the measured cases mean values are about 10 to 12 times higher than the peak time. 
P-control, $K=12$ 1/s, $m=850 \mathrm{~kg}$

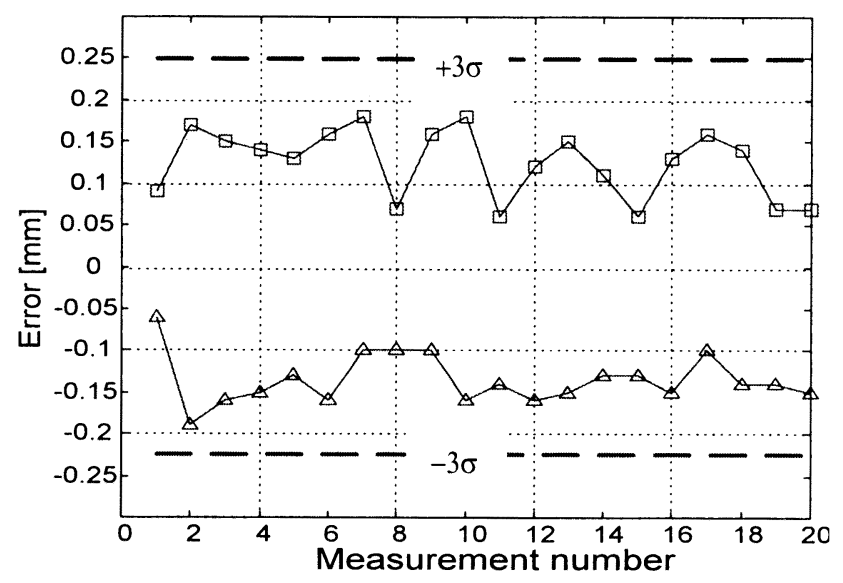

Figure 10 Position error deviation with $\mathrm{m}=850 \mathrm{~kg}$

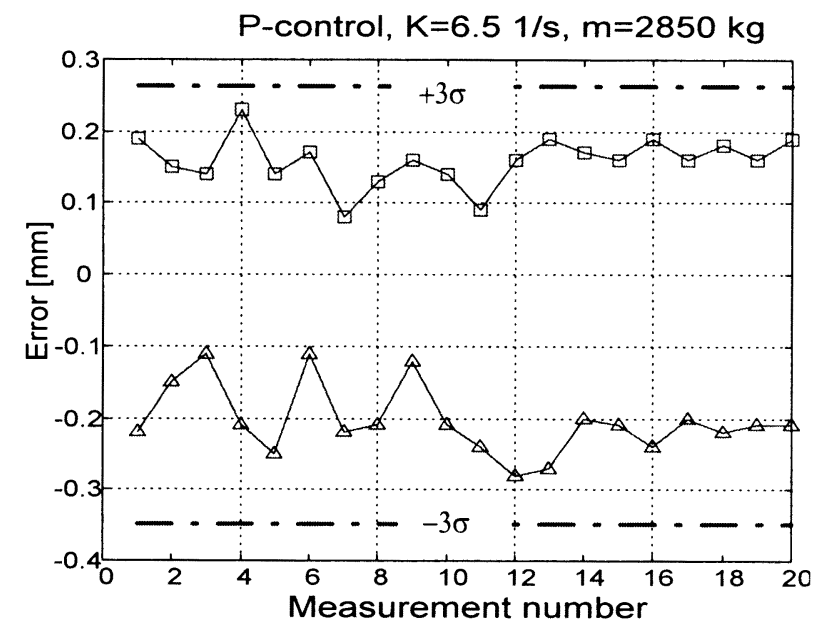

Figure 11 Position error deviation with $\mathrm{m}=2850 \mathrm{~kg}$

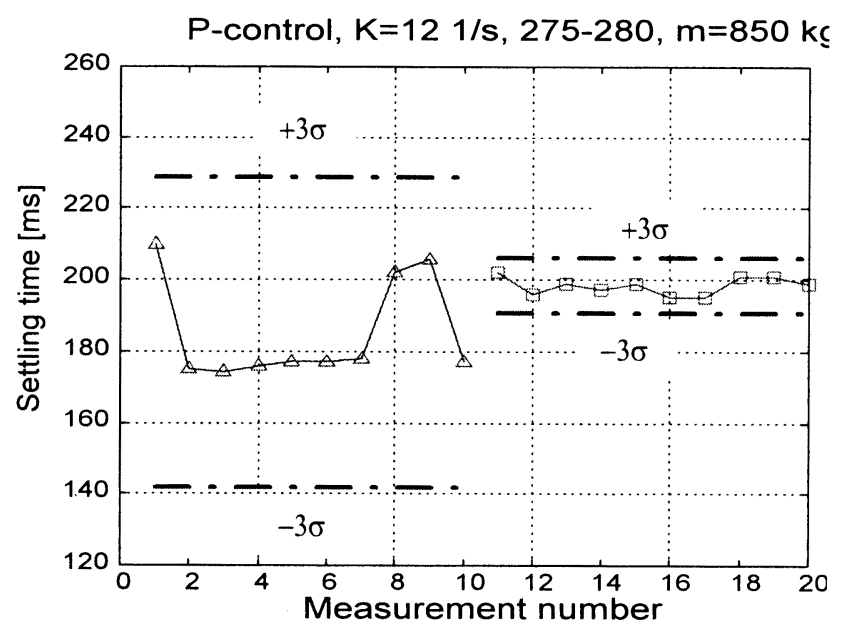

Figure 12 Settling times with $\mathrm{m}=850 \mathrm{~kg}$. Plus-movement is on the left side and minus-movement on the right side

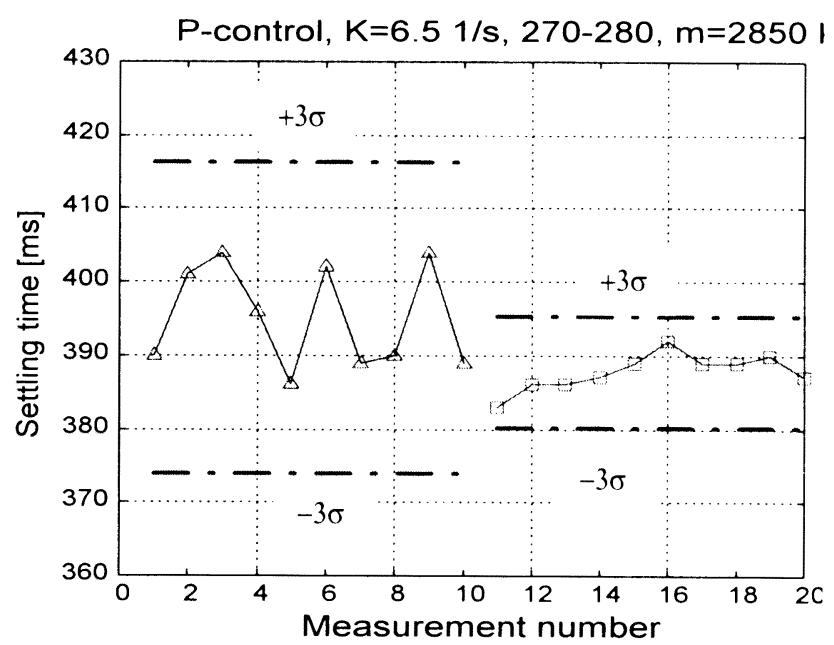

Figure 13 Settling times with $\mathrm{m}=2850 \mathrm{~kg}$. Plus-movement is on the left side and minus-movement on the right side

\section{CONCLUSIONS}

A design method similar to that used in oil hydraulic position servos works very well also with water hydraulics. The measured errors are very close to the desired values. Settling times are slightly long but nevertheless reasonable for the P-controlled position servo. The analysis of the oscillation behavior in the velocity curves also indicates that the actual natural frequency is somewhat smaller than expected and that the damping is greater.

The result with the P-controller is satisfactory, but the state controller, for example, might require more tuning since it affects the damping and natural frequency of the servo drive.

In the future natural frequency and damping in water hydraulic cylinder drives must be analyzed more exactly. Also different control algorithms and force, velocity and motion control must be studied more.

\section{REFERENCES}

1. Virvalo,T. Modeling hydraulic position servo realized with commercial components. $3^{\text {rd }}$ International Conference on Fluid Power Transmission and Control, Zhejiang University, Hangzhou China, 13-16 September 1993, 6p.

2. Viersma, T.J. Analysis, Synthesis and design of Hydarulic Servosystems and Pipelines. Elsevier Scientific Publishing Company, Amsterdam, The Netherlands 1980, 280 p. 